\title{
Dinámicas sociales y económicas dadas por el proceso de conurbación del municipio de Cota, Cundinamarca, Colombia
}

\section{Social and economic dynamics given by the conurbation process of the municipality of Cota, Cundinamarca, Colombia}

\author{
DOI: 10.17981/mod.arq.cuc.24.1.2020.10
}

Artículo. Fecha de Recepción: 09/04/2020. Fecha de Aceptación: 30/04/2020.

\section{Leonor Aydeé Hernández Ahumada}

Fundación Universitaria Agraria de Colombia - UNIAGRARIA (Colombia)

leonorhernandez127@gmail.com

Para citar este artículo:

Hernández, L. (2020). Dinámicas sociales y económicas dadas por el proceso de conurbación del municipio de Cota, Cundinamarca, Colombia MODULO ARQUITECTURA CUC, no. 24, pp. 191-208, 2020. DOI: http://doi.org/10.17981/mod.arq.cuc.24.1.2020.10

\section{Resumen}

El fenómeno de conurbación que ha afectado al municipio de Cota (Cundinamarca, Colombia) ha llevado a que se presenten nuevas dinámicas sociales y económicas en la región, ocasionando cambios en las actividades que allí se adelantaban. Se presentó un fenómeno de alta migración de habitantes nativos del municipio, cambio de actividades económicas, y una alta competencia por el uso del suelo, dejando por fuera el sector primario de la economía, al favorecer en primera instancia las nuevas actividades provenientes de la ciudad de Bogotá. Se realizó un estudio que permitió visualizar de manera clara, cómo el fenómeno cambió las tradiciones y afectó de manera directa a familias que dependían de la actividad agropecuaria.

Palabras clave: Expansión urbana; conurbación; rururbanización; sector agropecuario

\begin{abstract}
The phenomenon of conurbation that has affected the municipality of Cota (Cundinamarca, Colombia) has led to new social and economic dynamics in the region, causing changes in the activities that were carried out there. A phenomenon of high migration of native inhabitants of the municipality, change of economic activities, and high competition for land use, leaving out the primary sector of the economy, by favoring in the first instance the new activities coming from the city of Bogota. A study was carried out to clearly visualize how the phenomenon changed traditions and directly affected families that depended on agricultural activities.
\end{abstract}

Keywords: Urban expansion; conurbation; urbanization; agricultural sector 
INTRODUCCIÓN

La expansión urbana conlleva a que las grandes ciudades se desborden y se expandan hacia otros núcleos cercanos, integrando municipios no están preparados con infraestrueturas de servicios incapaces de satisfacer las necesidades de los nuevos habitantes y actividades económicas iniciadas alli. El objetivo de la presente investigación es estudiar el proceso de conurbación que ocurre en la Sabana de Bogotá, en específico, el Municipio de Cota (Cundinamarca), caracterizado económicamente por la actividad agrícola, principalmente el cultivo de hortalizas. Productores tradicionales de hortalizas, que han tenido que migrar a los límites del municipio a tierras en arriendo para seguir adelante con su actividad productiva (Figura 1). En el área pecuaria, predomina el ganado vacuno y caballar, y la atención al turista como otro frente económico. Se distingue por la producción agroindustrial y por ser eje de desarrollo industrial y urbanístico, dada su vecindad con la ciudad capital.

Figura 1. Productor tradicional de hortalizas. vente: Fotografía tomada por la autor

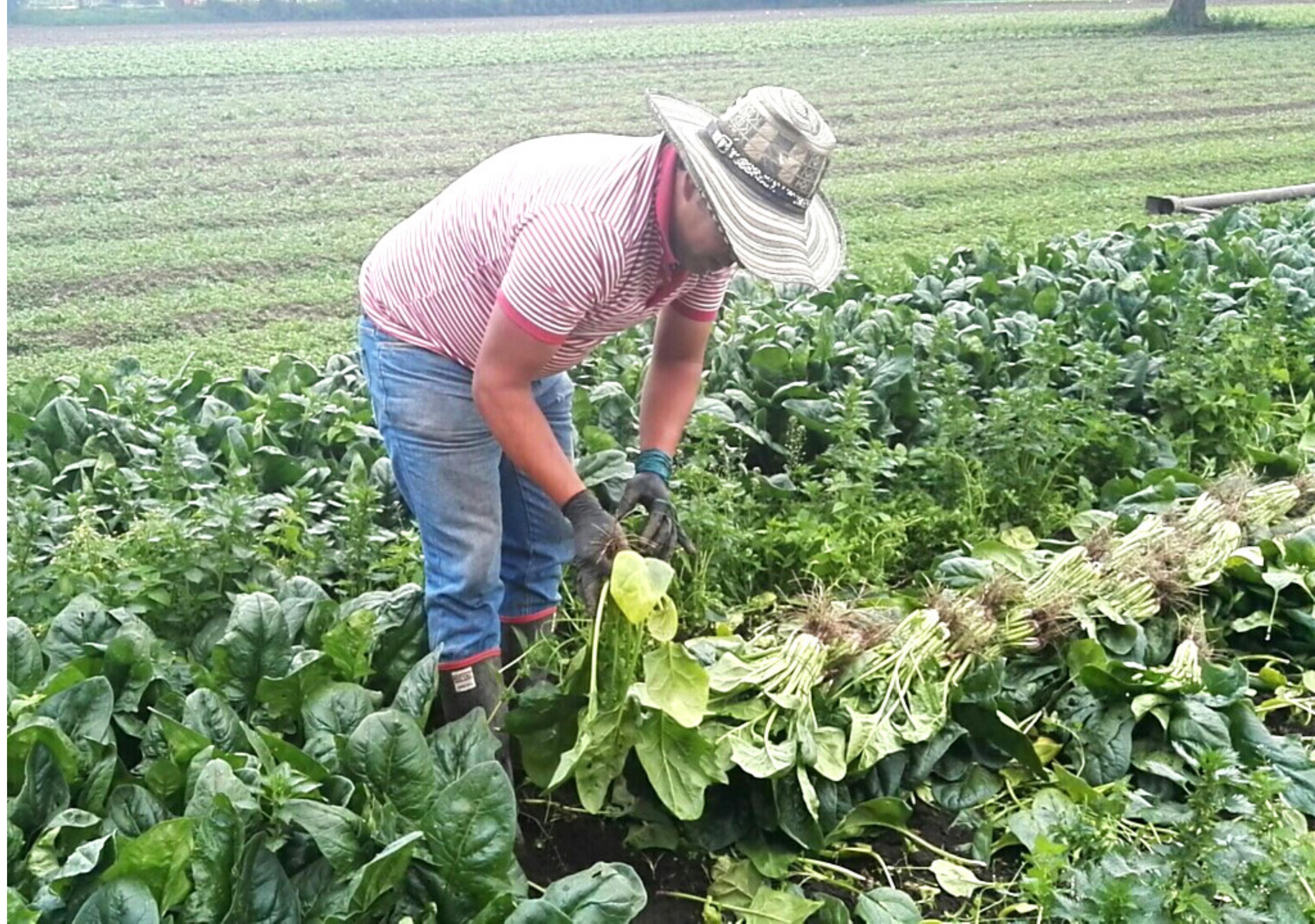


El municipio de Cota se encuentra ubicado en la llamada área metropolitana de Bogotá (ciudad capital de Colombia), en la provincia SabanaCentro. El municipio, tradicionalmente de producción agropecuaria, es receptor de la industria que ha sido expulsada de la ciudad capital, lo que ha conllevado a que ocurran procesos de rápida urbanización, ocasionando la ocurrencia de nuevas dinámicas sociales y económicas, que acaban con tradiciones, y tienden a generar movilización de población autóctona, perdiéndose las prácticas agropecuarias que por tradición allí se mantenían (Figura 2).
Cota - $-{ }^{\circ} \mathrm{C}$ 24.09.2016 
Por lo anterior, la economía del municipio se torna dinámica, ofreciendo oportunidades para los habitantes, pero generando cambios radicales en las actividades tradicionales que hace algunos años caracterizaban al municipio, se resta mano de obra para la actividad productiva, y en época de cosecha no es fácil la consecución de mano de obra para la realización de esta actividad. Es allí cuando las familias se unen para realizar dicha labor.

El arribo de nueva población al municipio ha generado que lleguen nuevas actividades económicas por la demanda de restaurantes, servicios de transporte, misceláneas, ampliación de cobertura de servicios públicos y comercializadoras en general, las cuales permiten a los habitantes de Cota emplearse en estas actividades, además de las propias generadas por la industria que ofrece vacantes de manera constante.

Evidentemente el primer renglón de la economía ya no es la producción de hortalizas. Ahora la economía del municipio se basa principalmente en el pago de impuestos generados de la zona industrial. Hay muchas empresas basadas en alimentación: Restaurantes, supermercados, y como ha sido la tradición, la elaboración de postres, lo cual es un atractivo que lleva turismo al municipio. En un comienzo la totalidad de los postres eran elaborados con la leche producida en el municipio, pero la ganadería de leche ha perdido espacio, y ya no se cuenta con el insumo suficiente para suplir este renglón de la economía.
En el marco de un mundo globalizado, en donde el acceso a la tecnología y comunicaciones cada vez es más sencillo, en un municipio tan cercano a la ciudad capital, y que hace parte del área metropolitana, el mantener una identidad marcada por una cultura y tradiciones agrícolas, demostrando que las actividades agrícolas y pecuarias que aún se mantienen, están dadas por su vocación, por arraigo y por la creencia ferviente en que la actividad desarrollada les permite llevar una vida digna, y que no deben irse en la búsqueda de sueños inciertos. Son pocas, pero aún persisten familias que insisten en trabajar en el reglón primario de la economía.

\section{Desarrollo}

El municipio de Cota o Quota (en lengua Muisca), ubicado en el departamento de Cundinamarca, Colombia, fue fundado el 29 de noviembre de 1604 por orden del oidor Diego Gómez de Mena. Tradicionalmente ha sido un municipio de vocación agrícola, siendo esta actividad tradicional el motor económico del territorio.

Económicamente, el municipio está dedicado a la agricultura, y a la atención al turista, predominando las ventas de comidas y platos típicos de la región, habiendo presencia de variados restaurantes de platos típicos. Predominan los cultivos de hortalizas y el ganado vacuno caballar. El Municipio se caracteriza por la producción agroindustrial y adicionalmente cuenta con una amplia zona franca. 
El área total del municipio es de 5.343,56 hectáreas (ha) distribuidas de manera general en aproximadamente 141,56 hectáreas pertenecientes al área urbana y 5.202 hectáreas al área rural. Según Muñoz (2017), la Corporación para el Fomento y Desarrollo Empresarial (CEFIN) reporta 448 productores agropecuarios activos, de los cuales se estima que "el $80 \%$ de estos cultivos son transitorios, en los que destacan: espinaca, maíz, papa, cilantro, zanahoria, arveja, lechuga batavia, lechuga crespa, aromáticas, rábano, acelga, entre otros" (p. 13). El 18\% de la producción corresponde a cultivos anuales como la papa criolla y la papa $\mathrm{R} 12$, y el restante $0.5 \%$ son cultivos perennes, frutales entre los que se destacan el tomate de árbol, feijoa y durazno (Moreno, 2008).

\section{Contexto histórico}

En el año 1604, se presenta el primer asentamiento colonial, en el sector conocido hoy en día como Hacienda el Arayán (Vereda Pueblo Viejo), posteriormente se hizo una repoblación en el año 1638 y otra nuevamente en 1670. La ubicación actual del municipio fue fundada por el General Alberto Urdaneta, en 1871 (Wiesner, 1996).

En el periodo republicano, el gobierno decreta varias disposiciones, entre las que estaban el dividir y repartir los resguardos indígenas, eso ocurre en el municipio de Cota, en donde la ubicación actual del resguardo no es la original. Entre los años 1804 y 1875 se llevan a cabo 15 transacciones de tierras a partir de la división de dos haciendas, son pequeños propietarios los compradores de estas tierras (Wiesner, 1996).
El Plan Básico de Ordenamiento Territorial (PBOT) del año 2000, da cuenta de cómo el fraccionamiento de la propiedad rural evidencia la demanda de tierra para diferentes actividades: agropecuarias tradicionales, vivienda campestre y la naciente dinámica de mercado de inmuebles rurales (Concejo Municipal de Cota, 2000).

Al inicio de la década de 1990, el municipio aún era pequeño y compacto, pero hacia el año 1995, desde la ciudad de Bogotá, se inicia un proceso de expansión copando muchos de los espacios intersticiales. El occidente por la vía al municipio de Cota se constituye como la tercera aglomeración más importante del área metropolitana. El fenómeno descrito está dado por el agotamiento del suelo urbanizable en la ciudad de Bogotá. (Santana, 2013)

En la ciudad de Bogotá se encontraban asentadas las grandes industrias, pero ante el rebose de las zonas industriales se ve la necesidad de reubicar la industria en los municipios aledaños. La Ley 1004 (2005) es la que promueve el establecimiento de zonas francas como la principal estrategia de competitividad, en el marco de la política neoliberal. Es entonces cuando se promueve la creación de parques industriales en el municipio de Cota en Cundinamarca, el cual cuenta con vías de acceso estratégicas que benefician a la industria.

En el año 2000 se da inicio a la planificación municipal en torno a los incentivos fiscales para las empresas tendientes a una exención tributaria durante ocho años, este primer cambio se da alrededor del Plan Básico de Ordenamiento 
Territorial (PBOT). En torno al PBOT se determina el cambio del uso del suelo hacia el uso agroindustrial.

En el periodo comprendido entre 2004 a 2008 se inicia la planificación de los parques industriales y la zona franca en un área establecida de 1450 hectáreas (UNCRD. Secretaría Distrital de Planeación, 2011)

Son políticas del gobierno central las que buscan fortalecer el tema competitivo con la creación de zonas francas que generen ingresos para los municipios que se "beneficien" de estas. Tal parece que los beneficios tributarios generan más interés que las actividades productivas del territorio y la conservación ambiental.

El informe de gestión entregado por la administración municipal del período $2004-2008$ reporta que la construcción de vivienda creció pasando del 4,7 al 11,8\% entre los años 2004 y 2006. Figura 3. Muestra del nuevo proyecto
de urbanización en el municipio de Cota Fuente: Fotografía tomada por la autor

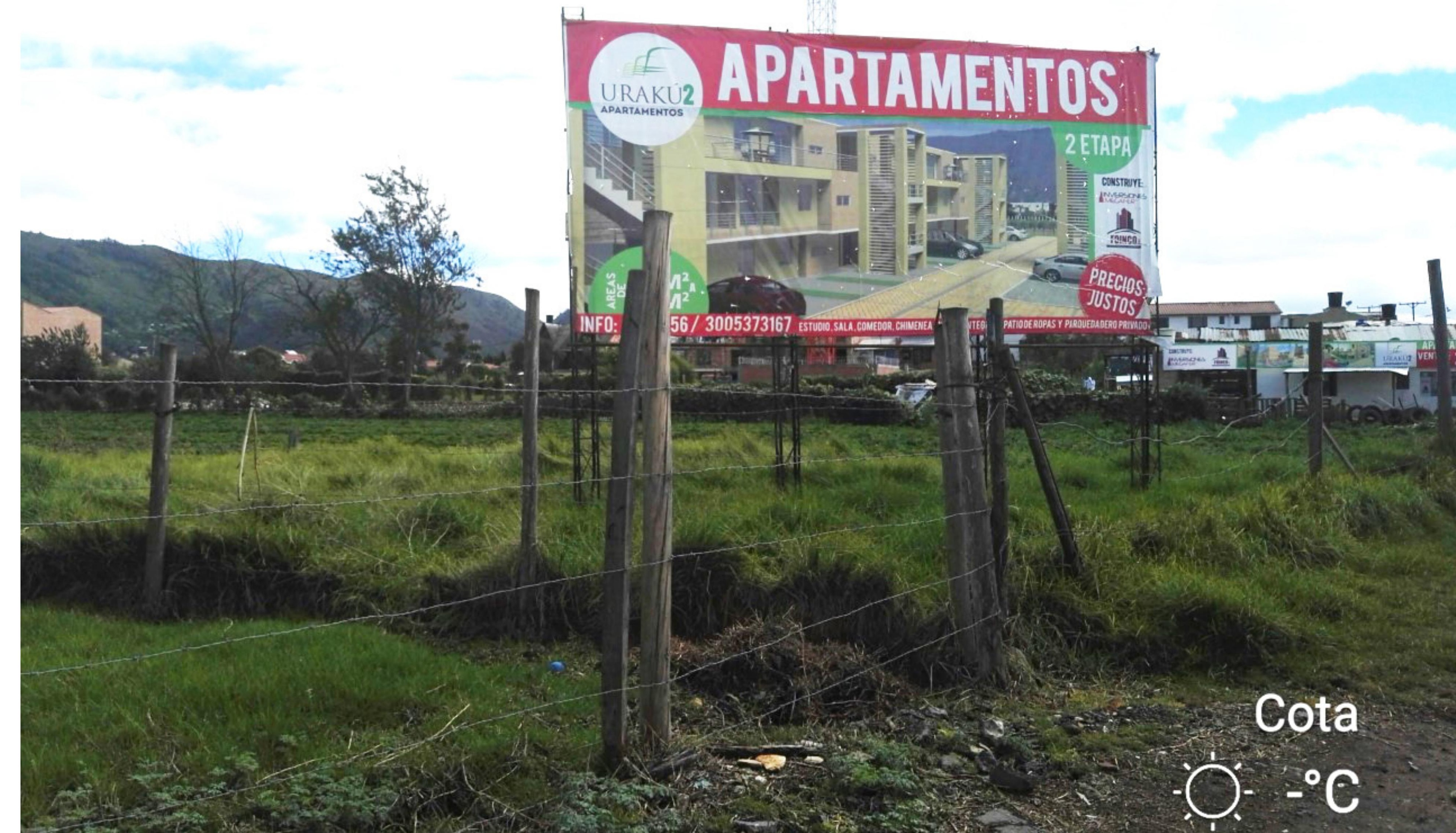


El crecimiento urbanístico ocasiona el incremento del valor del metro cuadrado del suelo urbano, y las construcciones de condominios general el alto costo del suelo rural, significativamente mayor que el costo del suelo urbano, no hay posibilidad de construcción de Vivienda de Interés Social (VIS), se genera alta tendencia del uso del suelo rural con fines urbanísticos, primando más los intereses de los ingresos generados por el pago de licencias de construcción y obviamente la administración pública local mejora sus ingresos por impuestos a lo urbano (Figura 3). Los habitantes del municipio en muchas ocasiones se suman a los proyectos urbanísticos.

Paradójicamente, el estudio de población del municipio evidencia que la población rural tiende a aumentar, lo cual puede estar generado por la llegada de nuevos habitantes provenientes de Bogotá. Puede afirmarse entonces, que hay un intercambio poblacional, en el cual los jóvenes rurales migran a las ciudades buscando mejores oportunidades y una posible mejora en su calidad de vida, y los habitantes de las ciudades buscan establecerse en el campo, en el cual ven un atractivo por su ambiente apacible, la cercanía a la ciudad, la búsqueda de la sencillez y tranquilidad. Lo anterior, le da un nuevo significado a lo rural, ahora también habitado por nuevos pobladores también llamados neorurales, generándose nuevas dinámicas sociales y actividades no relacionadas a la producción agropecuaria.

Ardila y Parra (2015), concluyen:
En cuanto a las áreas del suelo rural, es interesante observar la perdida de áreas rurales que ha venido sufriendo el municipio de acuerdo a las cifras del POT 2000 y PBOT 2014, de 2134 Hectáreas a 889,10 Hectáreas respectivamente, donde en un lapso de 14 años, el municipio ha perdido 1244,9 Ha, lo que representa el 58\% de su área rural, argumento que se refuerza con el histórico de subdivisión predial, los valores del suelo y el índice de ruralidad (p. 67).

Lo anterior lleva a un desequilibrio territorial, produciéndose procesos de conurbación, hay apertura de la frontera agrícola perdiéndose los límites y priorizando la urbanización (Ardila y Parra, 2015).

Es evidente que hay competencia y se generan tensiones de uso del suelo, los productores tienden a buscar suelo cultivable en la frontera municipal, tendiendo que pagar altos costos de la tierra y con bajo ingreso económico. Es allí cuando comienzan los procesos de migración principalmente por parte de los jóvenes que no encuentran opciones productivas en su propia tierra. La modernidad acaba con las tradiciones campesinas, priman los intereses individuales al bienestar colectivo.

En el marco de la formulación del Plan de Desarrollo del municipio de Cota (Consejo Municipal de Cota, 2016), se reporta que el área dedicada a la ganadería se presenta en la zona de Vuelta Grande y Parcelas. El plan establece que dichas zonas se han afectado por el cambio del uso del suelo, el cual se ha disminuido en un $50 \%$ durante los últimos 15 años. 
Según la Secretaría Agropecuaria Medioambiente y Desarrollo Económico (SAMADE, 2015), el área destinada a la producción agrícola esta alrededor de 460,71 ha, teniendo en cuenta el sector floricultor cuya área ocupada es de 82,49 ha.

Las anteriores situaciones frente al uso y tenencia de la tierra han generado el desplazamiento de la población campesina fuera del municipio o también han debido variar su actividad productiva (Moreno, 2008, p. 100).

El municipio de Cota no se ha visto afectado por condiciones de violencia marcadas, su principal característica es la cercanía a la ciudad capital, la cual por política de Estado ha expulsado a la industria hacia los municipios que corresponden a la llamada área metropolitana, pasando a ser este municipio receptor de estas grandes empresas que además fomentan procesos de rápida urbanización. Es entonces, cuando la población rural, ante todo la población joven, busca mejorar sus niveles de ingreso y estabilidad económica, vinculándose a la industria y construcción. Su salida del sector rural obedece entonces a procesos de escases de tierra.

Existen varios cultivos de flores que evidentemente suman dentro de las estadísticas de producción agropecuaria. El sector agropecuario no relacionado con esta actividad presenta bajos niveles de productividad, dado principalmente por los altos costos de la tierra y la falta de mano de obra, ya que las personas en edad productiva prefieren sumarse a la nómina de las grandes empresas pertenecientes a la zona franca establecida en el Municipio, es claro también que los insumos agropecuarios tienen alto costo, lo que repercute en bajos ingresos.

Los procesos de conurbación han llevado a que el suelo apto para la agricultura se esté agotando, y se encarezca el precio de la tierra, acabándose de manera progresiva la actividad agropecuaria, los jóvenes buscan entonces nuevas alternativas de supervivencia, movilizándose a las ciudades y zonas que ofrecen posibilidades laborales.

\section{Dinámica poblacional}

Según el Departamento Administrativo Nacional de Estadística (DANE), y las proyecciones estimadas para el año 2015, el total de la población es de 24.916, y para el año 2020 la población será de 27.496 habitantes (DANE, 2010).

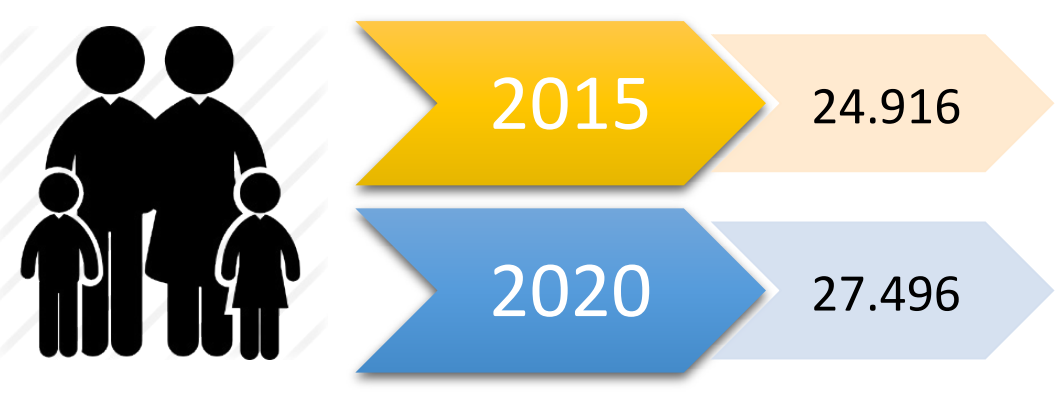

Figura 4. Estimación de población para el año 2020. Fuente: DANE (2010).

El Plan de Desarrollo Municipal 2016-2019 "Cota municipio ecoindustrial de la Sabana" (Consejo Municipal de Cota, 2016), hace mención del crecimiento poblacional acelerado en el municipio: 
Cota hace parte de un fenómeno denominado metropolización, de su entorno físico y poblacional por dos fenómenos ligados e interconectados. El primero se denomina conurbación, el cual se relaciona con la cercanía o proximidad con un centro urbano o varios de ellos, en este caso la ciudad de Bogotá y sus municipios vecinos; y por
otro lado, el fenómeno de integración sistémica, el cual es conexo con las dinámicas económicas que surgen entre las relaciones entre el municipio y su proximidad con un centro urbano de importancia, nuevamente la ciudad de Bogotá.
En este último se destacan los servicios ambien-

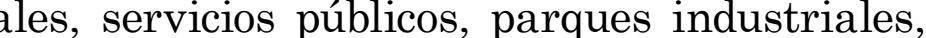

transporte y comercio, enmarcando el proceso

el norte de la capital (Moreno, 2008, p. 55).
El crecimiento poblacional parece estable, aunque tiende a aumentar debido a la llegada de nueva población de manera permanente al municipio, esto ocasona gran demanda de al vicios lo que requiere bajar la calidad de ser-

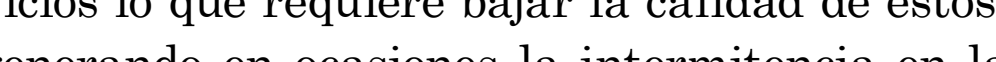
prestación de estos (Figura 5).

Figura 5. Evidencia de cómo las nuevas urbanizaciones

(3)

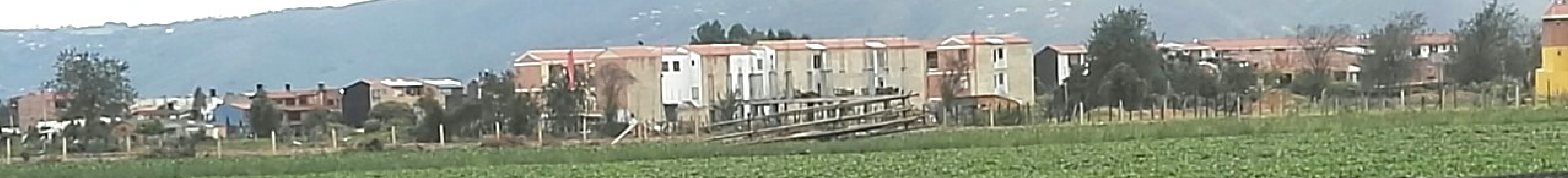

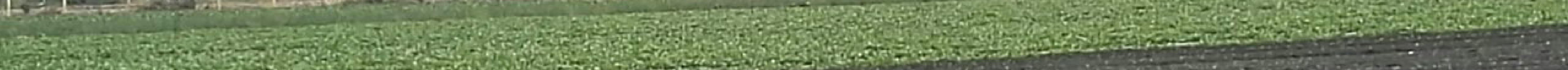

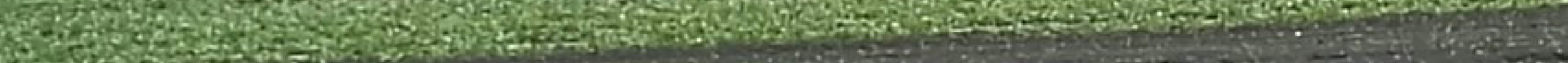

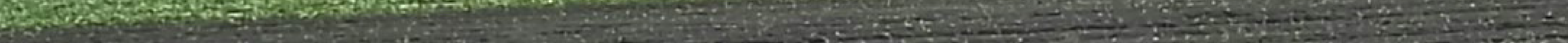

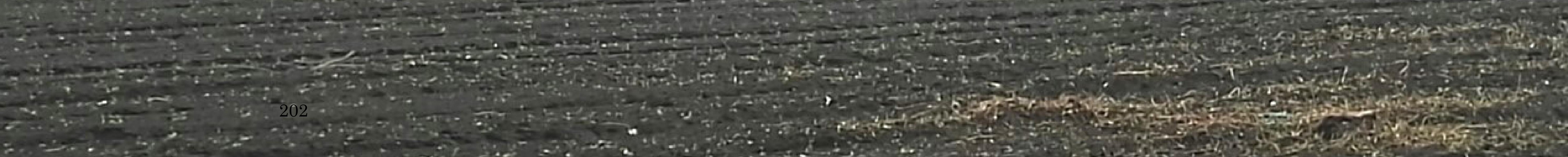




\section{Afectación productiva}

El municipio de Cota era reconocido por ser despensa de la Sabana, pero dada la rápida expansión urbana, la vocación se ha ido tornando agroindustrial. La población campesina migra, y aquellos que deciden permanecer en el territorio, deben cambiar su actividad productiva.

La Cámara de Comercio de Bogotá, destaca que, dentro de sector económico secundario, en el municipio se encuentra la pequeña, mediana y gran industria, lo que genera empleo, impuestos e ingresos por diferentes conceptos. El mismo documento dictamina que Cota es el municipio con mayor número de grandes empresas de Cundinamarca y la provincia (ESAP, 2013).

En el casco urbano, las actividades económicas que predominan son las del comercio de alimentos y víveres al por menor, restaurantes, telecomunicaciones, comercio de materias primas, transporte e inmobiliarias.

No deja de ser importante la producción agropecuaria del municipio que, aunque se ha visto afectada por la presión urbana, aún genera ingresos para quienes no han dejado la actividad.

Aunque se presentan algunas condiciones favorables como las descritas anteriormente, se tiene que son más las condiciones adversas. La mayoría de las familias productoras no cuentan con terreno propio para la producción, esto se debe a que la reglamentación del uso de suelo les ha obligado a vender los terrenos que tenían, aunque en muchos de los casos han recibido grandes sumas de dinero, son más los casos en los cuales no perciben el valor real. Aun así, persisten en la tradición productiva, pero se someten al pago de grandes sumas por el arriendo de parcelas aptas para el cultivo.

En cuanto al tema de mercadeo de los productos agropecuarios, la producción se destina principalmente a la central de abastos: Corabastos, mediante intermediación en gran parte y comercialización directa y de otro tipo en una mínima parte. Dentro de las estrategias implementadas por la SAMADE, para ampliar el mercado se encuentra la implementación de los mercados municipales.

Los Mercados Campesinos inician en el año 2012 con ocho Agricultores de tres veredas cercanas al casco urbano, son una iniciativa conjunta entre líderes productores agropecuarios y SAMADE, logrando comercializar sus productos de manera directa, sin intermediarios. Predominan en los mercados las hortalizas, aromáticas y medicinales y los derivados lácteos.

En el sector rural también predominan actividades de tipo turísticas, de producción artesanal, medio ambiental y mineras.

\section{El problema}

El municipio de Cota se caracteriza por ser afectado por la presión del:

Desarrollo urbano que soporta por razones del fenómeno de conurbación que genera Bogotá y el atractivo urbanístico que representa su localización geográfica, la calidad del paisaje y la infraestructura actual a desarrollarse en el corto plazo (ESAP, 2013, p. 9). 
Entre las características a destacar del municipio se registra que allí se tiene establecida la zona industrial de 1300 hectáreas, de estas se han desarrollado alrededor del 40 , este nuevo renglón de la economía permite ingresos por concepto de impuestos de industria y comercio, que fortalecen las finanzas municipales.

Dentro de las principales actividades económicas tradicionales en el municipio se encuentran las agrícolas, pecuarias, artesanales, comercio informal y las famiempresas, las cuales son entendidas como:

Una conjunción entre sistemas vivos y abiertos: familia y empresa, pertenecientes a la economía popular, donde el objetivo principal es la supervivencia propia y de su familia, generando autoempleo y ocupación a los miembros de la familia (Segovia, 2013, p. 3)

Los jóvenes rurales del municipio de Cota alternan el estudio con el trabajo, lo que ocasiona deserción escolar, a pesar de ser alta la cobertura escolar, los jóvenes no culminan el ciclo educativo.

El trabajo formal existe, en las grandes empresas presentes en una región que tiene una amplia zona franca, en la agricultura los jóvenes se emplean por jornales diarios, dos o tres días a la semana, y mientras la mujer devenga un dólar más una botella de leche, el hombre recibe 10 dólares por su trabajo diario. Lo anterior significa que el trabajo de la mujer no es valorado de la debida forma, a pesar de que ella combina las labores domésticas con los trabajos de finca.
Aunque es un municipio cercano a la ciudad, las oportunidades laborales para ellas son escasas en el sector rural, por lo general ellas salen hacia la ciudad para emplearse en oficios domésticos.

Los procesos de conurbación, entendidos como un fenómeno mediante el cual dos o más ciudades se integran territorialmente, independientemente de su tamaño, de sus características propias y de la adscripción administrativa que posean (Moreno, 2008), han llevado a que el suelo apto para la agricultura se esté agotando, y se encarezca el precio de la tierra, acabándose de manera progresiva la actividad agropecuaria, los jóvenes buscan entonces nuevas alternativas de supervivencia, movilizándose a las ciudades y zonas que ofrecen posibilidades laborales.

\section{Conclusiones}

Para los municipios cercanos a grandes ciudades es prioritario que establezcan procesos de planeación que permitan valorar las tradiciones de los habitantes, ya que aunque cuentan con independencia administrativa, suelen ser los primeros afectados por el acelerado crecimiento de las urbes.

El establecimiento claro de fronteras agropecuarias permite, que la llegada de industria y nuevos pobladores no afecten a los pobladores de la región. Esto se logra respetando la reglamentación de uso del suelo, sin cambiarla de manera arbitraria, permitiendo así garantizar la estabilidad económica de los habitantes de los municipios. 
A pesar de los controles que se hacen en materia ambiental, la nueva industria y nuevas urbanizaciones ocasionan un desbalance que genera una excesiva generación de desechos, en muchas ocasiones de carácter tóxico, que no es soportado por las redes de alcantarillado, y terminan colapsando las redes de servicios. Los municipios no cuentan con los equipamientos, ni la infraestructura requerida para recibir de manera masiva pobladores ni industria, aunque esta represente un nievo renglón de la economía en las regiones (Figura 6).

Figura 6. Las nuevas urbanizaciones se abren paso entre los terrenos aptos para la agricultura.

Fuente: Fotografía tomada por la autora

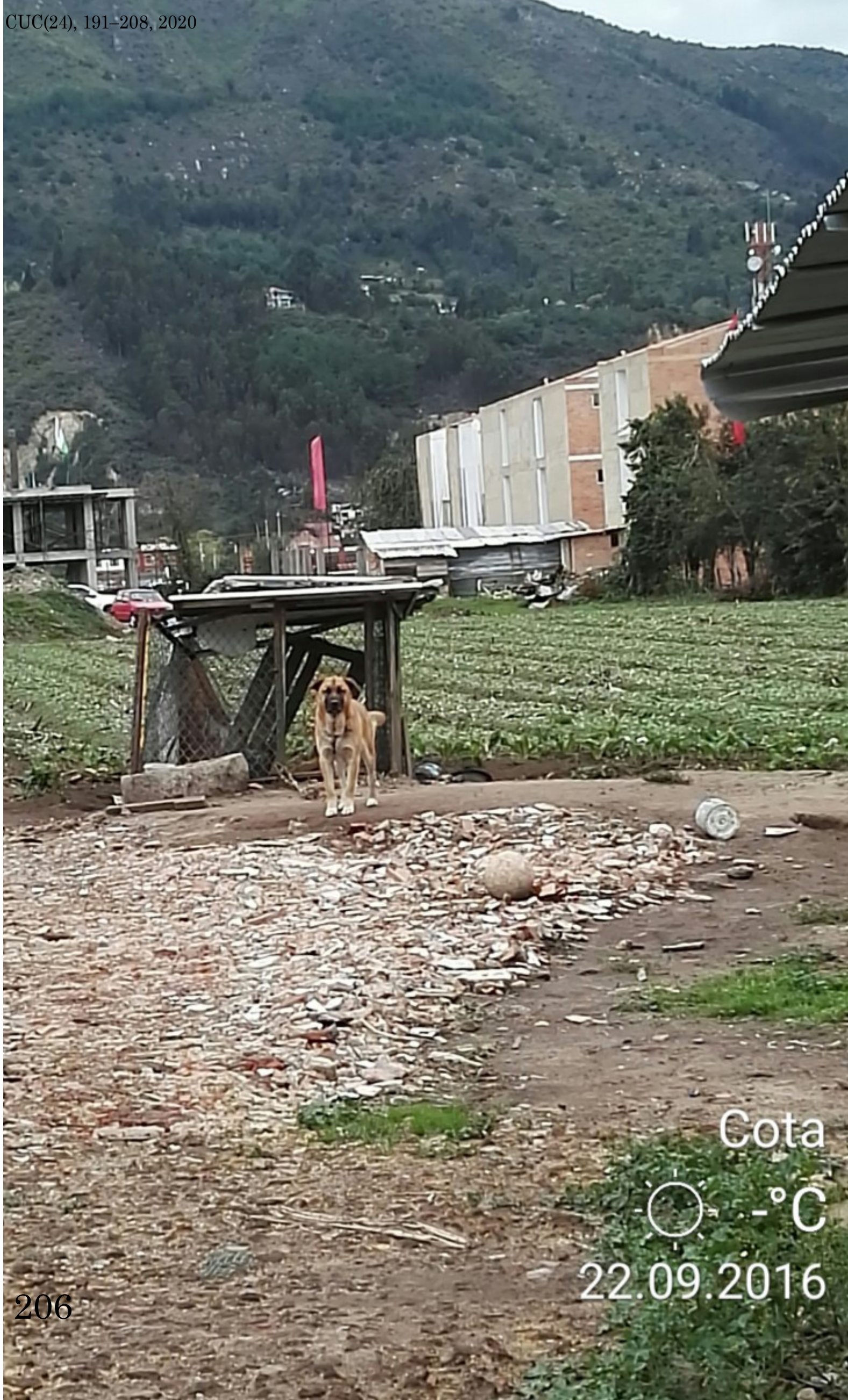




\section{REFERENCIAS}

Ardila, R. L. y Parra, L. A. (2015). Caracterización y análisis de los actores, discursos e imaginarios sociales que inciden en el proceso de urbanización y transformación rural en el municipio de Cota, Cundinamarca. [Trabajo magistral]. Universidad de La Salle, Bogotá, D.C., Colombia. Disponible en https://ciencia.lasalle.edu.co/ maest_gestion_desarrollo/80/

DANE. (2010). Proyecciones nacionales y departamentales de población 2005-2020. [Estudios Poscensales No. 7]. Bogotá, D.C.: Centro Andino de Altos Estudios, CANDANE. Disponible en https://www.dane. gov.co/files/investigaciones/poblacion/ proyepobla06_20/7Proyecciones_ poblacion.pdf

ESAP. Escuela Superior de Administración Pública. (2013). Informe ejecutivo de gestión. [Online]. Cota: ESAP. Disponible en http://cdim.esap.edu.co

Municipio de Cota. Concejo Municipal. (2016). Plan de Desarrollo Municipal 2016-2019. [Online]. Disponible en https://www.cotacundinamarca.gov.co/Paginas/default. aspx

Municipio de Cota. Concejo Municipal. (20 de Octubre de 2000). Plan Básico de Ordenamiento Territorial. [Acuerdo No. 012]. PBOT, 119-381. Disponible en http:// www.concejo-cota-cundinamarca.gov.co/ biblioteca-documental/acuerdo-12-de-2000
Moreno, C. (2008). La conurbación: rizoma urbano y hecho ambiental complejo. VII Seminario Nacional de Investigación Urbana Regional, Diversidad y desigualdad, ACIUR, Universidad Nacional de Colombia, Medellín, Colombia. Recuperado de http://www.bdigital.unal.edu.co/3363/1/ CIM-CONURBACION.pdf

Muñoz, G. (2017). Creación del Sistema Municipal de Apoyo a la Economía Campesina (SIMAECA) en el Munciipio de Cota-Cundinamarca. [Proyecto Especialización]. Universidad Nacional y Abierta a Distancia, Zipaquirá, Colombia. Disponible en https://repository.unad.edu.co/handle/10596/13433

República de Colombia. Congreso de Colombia. (30 de diciembre de 2005). Por la cual se modifican un régimen especial para estimular la inversión y se dictan otras disposiciones. [Ley 1004]. Diario Oficial: 46.138.

SAMADE. (2015). SAMADE. [Online]. Disponible en https://www.cota-cundinamarca.gov.co/SECRETARIAS YENTIDADES/Paginas/Secretaria-Agropecuaria-Medio-Ambiente-y-DesarrolloEcon\%C3\%B3mico(SAMADE).aspx

Santana, L. D. (2013). Precariópolis y privatópolis en la región metropolitana de Bogotá (1990-2010). Un análisis socioespacial de los barrios cerrados. [Tesis Magistral]. Universidad Nacional de Colombia, Bogotá, D.C., Colombia. Disponible en http:// bdigital.unal.edu.co/11228/ 
UNCRD. Secretaría Distrital de Planeación. (2011). Lineamientos para una política de adaptación a la evolución de los asentamientos productivos en la estructura metropolitana y regional Bogotá - Sabana. Bogotá, D.C.: Secretaría Distrital de Planeación Centro de las Naciones Unidas para el Desarrollo Regional - UNCRD. Recuperado de http:// www.sdp.gov.co/sites/default/files/pa002-1lineamientospoliticaadaptacion.pdf

Segovia, A. (2013). Las famiempresas: más que unidades de producción económica, una oportunidad para la intervención social. Trabajo Social, 15(15), 87-104. http://dx.doi. org/10.15446/ts
Wiesner, L. (1996). Etnografía Muisca: el Resguardo de Cota. En, X. Pachón, D. oliveros y L. Wiesner, Geografía Humana de Colombia. Región Andina Central. t. IV. vol. II (pp. 141-180). Bogotá, D.C.: Instituto Colombiano de Cultura Hispánica. Disponible en http:// babel.banrepcultural.org/cdm/ref/collection/ p17054coll10/id/2778

Leonor Aydeé Hernández Ahumada es Zootecnista con Magíster en Desarrollo Rural y docente de la facultad de Medicina Veterinaria en la Fundación Universitaria Agraria de Colombia - Uniagraria (Colombia). 